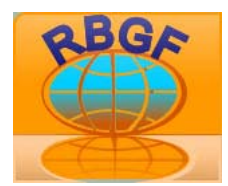

RBGF- Revista Brasileira de Geografia Física

Recife-PE Vol.1 n.02 Set/Dez 2008,30-49

\title{
CARACTERIZAÇÃO AMBIENTAL DA BACIA HIDROGRÁFICA DO RIO MOXOTÓ - PE USANDO SENSORIAMENTO REMOTO TERMAL
}

\author{
Tiago Henrique de Oliveira ${ }^{1}$ \\ Josiclêda Domiciano Galvíncio
}

Artigo recebido em 06-04-2009 e aceito para publicação em 11-05-2009

\begin{abstract}
RESUMO
Os produtos do Sensoriamento Remoto orbital vêm se tornando uma importante ferramenta para as mais variadas aplicações, particularmente aquelas relacionadas com a avaliação, manejo, gerenciamento e gestão de recursos naturais, como água, solo e vegetação. Este estudo visa realizar uma caracterização ambiental da Bacia Hidrográfica do Rio Moxotó, através do balanço de radiação. Para isto foram utilizadas duas imagens do mapeador temático do satélite Landsat 5 de órbita e ponto 215/66 com passagem em 27-09-1992 e 12-10-2003, que foram processadas, organizadas e analizadas em ambiente GIS. A diminuição da cobertura vegetal é evidente na análise temporal e espacial das duas datas analisadas. Esta diminuição fez com que em algumas áreas da bacia ocorresse um aumento de temperatura. As áreas de cimeira, com altitudes superiores a $600 \mathrm{~m}$ apresentaram índices de SAVI com valores superiores a 0.211 . Já as áreas com vegetação de encosta apresentaram valores de SAVI que variaram entre 0.130 e 0.210 . Em geral, ocorreu um aumento do Albedo, entre 27 de agosto de 1992 e 12 de setembro de 2003 e na bacia hidrográfica do rio Moxotó. No geral as áreas mapeadas como áreas de solo exposto e/ou atividades antrópicas apresentaram uma diminuição na densidade da cobertura vegetal e consequentemente aumento nos valores de albedo e temperatura.
\end{abstract}

Palavras chaves: Manejo, recursos hídricos, SEBAL, Landsat 5.

\section{ENVIRONMENTAL CHARACTERIZATION OF THE RIO MOXOTÓ - PE WATERSHED USING REMOTE SENSING THERMAL}

\begin{abstract}
The products of Orbital Remote Sensing have become an important tool for several applications, particularly those related to the assessment, management, management and management of natural resources such as water, soil and vegetation. This study aims at an environmental characterization of the River Watershed Moxotó through of the radiation balance. Were used for this two Thematic Mapper images of the Landsat 5 satellite from orbit and the crossing point 215/66 in 27-09-1992 and 12-10-2003, which were processed, organized and analyzed in GIS environment. The reduction of vegetation cover is evident in the temporal and spatial analysis of the two dates examined. This decrease has made in some areas of the basin was an increase in

\footnotetext{
${ }^{1}$ Graduando em Geografia do Departamento de Ciências Geográficas da Universidade Federal de Pernambuco (UFPE), bolsista PIBIC pelo CNPq., Centro de Filosofia e Ciências Humanas, Avenida Professor Moraes Rego, 1235, Cidade Universitária, Recife, Pernambuco. CEP 50670-901. (thdoliveira5@gmail.com).

${ }^{2}$ Professora adjunta do. Departamento de Ciências Geográficas da Universidade Federal de Pernambuco (UFPE) Centro de Filosofia e Ciências Humanas, Avenida Professor Moraes Rego, 1235, Cidade Universitária, Recife, Pernambuco. CEP 50670-901 (josicleda@pq.cnpq.br)
} 


\section{RBGF- Revista Brasileira de Geografia Física \\ Recife-PE Vol.1 n.02 Set/Dez 2008,30-49}

temperature. The areas with altitudes above $600 \mathrm{~m}$ had rates of SAVI with values greater than 0,211 . Those areas with vegetation of slope values of SAVI showed that varied between 0130 and 0,210. In general, there was an increase in albedo from 27 August 1992 and 12 September 2003 and in the basin of the river Moxotó. In general the areas mapped as areas of exposed soil and / or human activities showed a decrease in the density of vegetation cover and consequently increase in the values of albedo and temperature.

Keywords: Management, water resources, SEBAL, Landsat 5.

\section{INTRODUÇÃO}

Estudos climáticos envolvendo radiação solar e terrestre são importantes, pelo fato de ser esta a principal fonte de energia para os processos físicos $\mathrm{e}$ biológicos na atmosfera (Leitão, 1994). A vegetação é um importante receptor e armazenador de radiação solar, o que ocorre devido à absorção de energia incidente pelo sistema solo-planta, e é dependente do albedo da superfície (Jarvis et. al., 1997). As trocas de energia na interface vegetação-atmosfera, que ocorrem por meio dos componentes do balanço de radiação e dos fluxos de calor sensível e calor latente à superfície, são essenciais para modelagem climática e hidrológica, sendo a magnitude desses fluxos, e suas variações em períodos menores que um dia, muito importantes na calibração de modelos climáticos e hidrológicos (Baldocchi e Meyers, 1998). Em intervalos maiores, essas grandezas também são utilizadas em modelos de impactos climáticos globais resultantes de interações fisiográficas da superfície.
Um dos principais elementos climatológicos que compromete a evaporação da água do solo e a transpiração das plantas é a radiação solar, fator condicionante das temperaturas do ar e do solo (Pereira et al., 2006). Em relação às práticas de manejo da água na agricultura, o saldo de radiação solar é um dos fundamentais parâmetros atuantes na perda de água pelos vegetais, na decomposição da matéria orgânica e nos processos metabólicos e biológicos (Ometto et al., 1973; Critchfield, 1974). Segundo Gates (1965) e citado por Oliveira \& Leitão (2000), os vegetais absorvem cerca de $50 \%$ da radiação de ondas curtas incidentes e $97 \%$ da radiação de ondas longas proveniente da atmosfera. A razão entre as radiações de ondas curtas refletidas e incidentes é denominada coeficiente de reflexão ou albedo.

O coeficiente de reflexão de uma superfície vegetada varia ao longo do período diurno, em função do ângulo de elevação do Sol e ao longo do ciclo de desenvolvimento da planta, em função do grau de cobertura vegetal, tipo e estado de umidade do solo, condições de umidade do ar e da quantidade e tipo de 


\section{RBGF- Revista Brasileira de Geografia Física \\ Recife-PE Vol.1 n.02 Set/Dez 2008,30-49}

cobertura de nuvens (Blad \& Baker, 1972; Leitão, 1989; Azevedo et al., 1990). A radiação solar se distribui em diferentes faixas de comprimentos de onda que terão diferentes efeitos sobre as plantas, sendo a faixa que abrange a luz visível detectada pela retina humana compreendida entre 0,36 e $0,74 \mu \mathrm{m}$ (Liu et al., 2003). Se aceita hoje que, entre as condições planetárias básicas para que possa existir vida tal como a conhecemos, seja essencial a presença de água no estado líquido, em quantidade suficiente e energia solar em quantidade adequada, fornecendo luz e calor (Pitombo \& Lisboa, 2001).

Os estudos microclimáticos em comunidades vegetais têm enfocado medidas de radiação solar, uma vez que o balanço de radiação determina a disponibilidade energética para processos como evapotranspiração, aquecimento e resfriamento do ar e solo e a fotossíntese. No caso de uma floresta, os estudos microclimáticos envolvem a caracterização do ambiente que se estende desde alguns metros acima das copas das árvores, até o interior destas, no sub-bosque ou nas primeiras camadas do solo (CABRAL et al., 1996). Avaliações microclimáticas comparando o interior da floresta com áreas abertas, geralmente pastagem, são interessantes para dar uma idéia das modificações ambientais provocadas pela retirada da floresta. Essa informação é importante para o entendimento do manejo da regeneração natural em áreas degradadas ou até em estudos sobre mudanças climáticas em função do desmatamento (GIAMBELLUCA et al., 1997; HOLL, 1999).

Em geral, os componentes do balanço de energia são obtidos com equipamentos que fornecem apenas uma leitura pontual do saldo de radiação, e a implantação desses equipamentos em áreas amplas tornaria esse tipo de medição muito oneroso. Tendo em vista a importância deste dado o Sensoriamento Orbital tem se tornado uma importante ferramenta para obtenção deste.

Silva et al (2005) afirma que o saldo de radiação é uma informação de ampla importância, visto que a mesma é variável básica para a estimativa da evapotranspiração (ET) e no cálculo do balanço hídrico, essenciais para a utilização racional dos recursos hídricos. O autor ainda afirma que o SEBAL (Surface Energy Balance Algorithm for Land) é amplamente utilizado nos estudos dos valores do fluxo de calor latente e sensível à superfície (Bastiaanssen et al., 1998a,b; Bastiaanssen, 2000; Morse et al., 2001; Allen et al., 2002) e na obtenção do Saldo de Radiação de uma determinada área (Bastiaanssen et al., 1998a,b; 


\section{RBGF- Revista Brasileira de Geografia Física \\ Recife-PE Vol.1 n.02 Set/Dez 2008,30-49}

Boegh et al., 2002; Dubayah, 1992; Silva et al., 2004; Granger, 2000).

Diante do exposto, o objetivo deste estudo é afetuar uma caracterização ambiental da Bacia Hidrográfica do Rio Moxotó, através do balanço de radiação.

\section{MATERIAL E MÉTODO}

\section{A área de estudo}

A Bacia Hidrográfica do Rio Moxotó, Figura 1, inserida totalmente dentro dos limites do semi-árido nordestino, situase quase que totalmente na porção central do estado de Pernambuco e na parte oeste do estado de Alagoas, perfazendo uma área de aproximadamente $9.752,71 \mathrm{~km}^{2} \quad(8.778,05$ $\mathrm{km}^{2}$ no estado de Pernambuco e 974,66 km² no estado de Alagoas).

Fazendo parte da Bacia Hidrográfica do Rio São Francisco, no estado de Pernambuco constitui-se na Unidade de Planejamento Hídrico UP8, estando inserida nas microrregiões do Sertão do Moxotó (predominantemente), do Vale do Ipanema e de Itaparica (Pernambuco, 1999). No meio curso do rio Moxotó, foi construída a Barragem Poço da Cruz, obra realizada com objetivo de minimizar os efeitos danosos decorrentes dos longos períodos de estiagem.

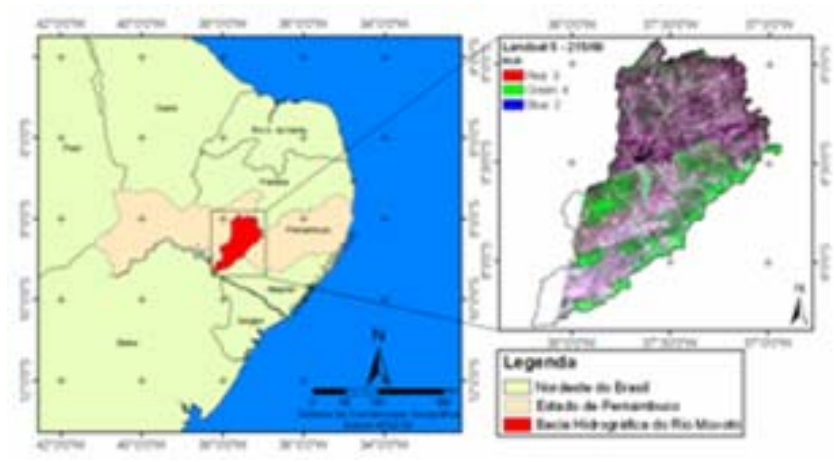

Figura 1. Mapa de localização da Bacia Hidrográfica do Rio Moxotó.

No pré-processamento das imagens de satélite, aplicação dos índices escolhidos e montagem final dos layout foi utilizado o software Erdas Imagine 9.3 e ArcGIS 9.3 (licença do Departamento de Ciências Geográficas da UFPE).

$\mathrm{Na}$ realização deste artigo foram utilizada imagens do Mapeador Temático do satélite Landsat 5, composta por sete bandas espectrais, adquiridas gratuitamente através de acesso ao catalogo de imagens do Instituto Nacional de Pesquisas Espaciais (INPE). A passagem pela Bacia Hidrográfica, ocorreram nos dias 27 de setembro de 1992 e 12 de outubro de 2003, na órbita e ponto 215/66. Os coeficientes de calibração utilizados nesta pesquisa são os mostrados na tabela 1. A metodologia empregada é a mesma utilizada por Silva et al (2005) e proposta por Bastiaanssen et al (1998a; 1998b) que consiste em: 


\section{RBGF- Revista Brasileira de Geografia Física \\ Recife-PE Vol.1 n.02 Set/Dez 2008,30-49}

Tabela 1. Descrição das bandas do Mapeador Temático (TM) do Landsat 5, com os correspondentes intervalos de comprimento de onda, coeficientes de calibração (radiância mínima - a e máxima - b) e irradiâncias espectrais no topo da atmosfera (TOA).

\begin{tabular}{|l|c|c|c|c|}
\hline \multicolumn{1}{|c|}{ Bandas } & $\begin{array}{c}\text { Comprimento de } \\
\text { Onda }(\boldsymbol{\mu m})\end{array}$ & \multicolumn{2}{|c|}{$\begin{array}{c}\text { Coef. de Calibração } \\
\left(\mathbf{W m} \mathbf{m}^{-\mathbf{2}} \mathbf{s r}^{-\mathbf{1}} \boldsymbol{\mu \mathbf { m } ^ { - 1 } )}\right.\end{array}$} & $\begin{array}{c}\text { Irradiância Espectral no } \\
\text { Topo da Atmosfera } \\
\left(\mathrm{Wm}^{2} \boldsymbol{\mu m}{ }^{-1}\right)\end{array}$ \\
\hline Banda 1 (azul) & $0,45-0,52$ & -1.500 & 152.100 & 1957 \\
\hline Banda 2 (verde) & $0,52-0,60$ & -2.800 & 296.800 & 1829 \\
\hline Banda 3 (vermelho) & $0,63-0,69$ & -1.200 & 204.300 & 1557 \\
\hline Banda 4 (IV-próximo) & $0,76-0,79$ & -1.500 & 206.200 & 1047 \\
\hline Banda 5 (IV-médio) & $1,55-1,75$ & -0.370 & 27.190 & 219,3 \\
\hline Banda 6 (IV-termal) & $10,4-12,5$ & 1.238 & 15.600 & - \\
\hline Banda 7 (IV-médio) & $2,08-2,35$ & -0.150 & 14.380 & 74,52 \\
\hline
\end{tabular}

\section{Calibração Radiométrica}

Consiste no cômputo da radiação espectral em cada banda $\left(L_{\lambda_{i}}\right)$, em que o número digital (ND) de cada pixel da imagem é convertido em radiância espectral monocromática. A equação utilizada é a proposta por Markham e Baker (1987) (Eq. 1):

$\mathrm{L}_{\lambda \mathrm{i}}=\mathrm{a}_{\mathrm{i}}+\frac{\mathrm{b}_{\mathrm{i}}-\mathrm{a}_{\mathrm{i}}}{255} \mathrm{ND}$

em que "a" e "b" são as radiâncias espectrais mínimas e máximas $\left(\mathrm{Wm}^{-2} \mathrm{sr}^{-1} \mu \mathrm{m}^{-1}\right)$, ND é a intensidade do pixel (numero inteiro compreendido entre 0 e 255) e i corresponde as bandas $(1,2, \ldots$ e 7$)$ do satélite Landsat 5 .

\section{Reflectância}

Esta pode ser definida como sendo a razão entre o fluxo de radiação refletida e o fluxo de radiação incidente que é obtida segundo a equação (Allen et al., 2002) (Eq. 2):

$\rho_{\lambda \mathrm{i}}=\frac{\pi \cdot \mathrm{L}_{\lambda \mathrm{i}}}{\mathrm{k}_{\lambda \mathrm{i}} \cdot \cos Z \cdot \mathrm{d}_{\mathrm{r}}}$

onde $\mathrm{L}_{\lambda \mathrm{i}}$ é a radiância espectral de cada banda, $\mathrm{k}_{\lambda \mathrm{i}}$ é a irradiância solar espectral de cada banda no topo da atmosfera $\left(\mathrm{Wm}^{-2} \mu \mathrm{m}^{-1}\right.$, Tabela 1$)$, $\mathrm{Z}$ é o ângulo zenital solar e $\mathrm{d}_{\mathrm{r}}$ é o quadrado da razão entre a distância média Terra-Sol $\left(r_{0}\right)$ e a distância Terra-Sol (r) em dado dia do ano (DSA). 


\section{RBGF- Revista Brasileira de Geografia Física}

Recife-PE Vol.1 n.02 Set/Dez 2008,30-49

\section{Albedo planetário (atoa)}

O albedo não corrigido (Eq. 3) é efetuado através da combinação linear das reflectâncias monocromáticas:

$\alpha_{\text {toa }}=0,293 \rho_{1}+0,274 \rho_{2}+0,233 \rho_{3}+0,157 \rho_{4}+0,033 \rho_{5}+0,011 \rho_{7}$

onde $\rho_{1}, \rho_{2}, \rho_{3}, \rho_{4}, \rho_{5}$ e $\rho_{7}$ são os albedos planetários das bandas 1, 2, 3, 4, 5 e 7 .

\section{Transmissividade Atmosférica}

Em condições de céu claro, pode ser obtida por (Allen et al., 2002) (Eq. 4):

$\tau_{\mathrm{sw}}=0,75+2 \cdot 10^{-5} \mathrm{z}$

onde $\mathrm{Z}$ corresponde a altitude de cada pixel (m). Devido à área apresentar uma grande variação de altitude se fez necessário à utilização de um Modelo Digital de Elevação (MDT) da área.

\section{Albedo à superfície $(\alpha)$}

O albedo a superfície (Eq. 4) é o albedo corrigido pelos valores do efeito atmosférico

$\alpha=\frac{\alpha_{\mathrm{toa}}-\alpha_{\mathrm{p}}}{\tau_{\mathrm{sw}}{ }^{2}}$

onde $\alpha_{p}$ é a radiação solar refletida pela atmosfera, variando entre 0,025 e 0,04 . Bastiaanssen (2000) afirma que o valor mais recomendado para o SEBAL seja o de 0,03, e $\tau_{\mathrm{sw}}$ é a transmissividade atmosférica, obtida para condições de céu claro em função da altitude de cada pixel, por equação proposta por Allen et al. (2002).
NDVI

O Índice de Vegetação da Diferença Normalizada (Normalized Difference Vegetation Index - NDVI) é obtido através da razão entre a diferença das refletividades do infravermelho próximo $\left(\rho_{\text {IV }}\right)$ e do vermelho $\left(\rho_{\mathrm{V}}\right)$, e a soma das mesmas:

$$
\mathrm{NDVI}=\frac{\rho_{\mathrm{IV}}-\rho_{\mathrm{V}}}{\rho_{\mathrm{IV}}+\rho_{\mathrm{V}}}
$$

onde $\rho_{\mathrm{IV}}$ e $\rho_{\mathrm{V}}$ correspondem, respectivamente, às bandas 4 e 3 do Landsat 5 - TM.

O NDVI atua como um indicador sensível da quantidade e da condição da vegetação verde. Seus valores variam de -1 a +1 . Para superfícies com alguma vegetação o NDVI varia de 0 e 1 ; já para a água e nuvens o NDVI geralmente é menor que zero.

\section{SAVI}

Heute (1988) propôs um índice de vegetação ajustado por solo (Soil adjusted Vegetation Index - SAVI) introduzindo um fator no NDVI para incorporar o efeito da presença do solo, mantendo-se o valor do NDVI dentro de -1 a +1 . Esse índice é calculado pela equação (Eq. 7):

$\mathrm{SAVI}=\frac{(1+\mathrm{L})\left(\rho_{\mathrm{IV}}-\rho_{\mathrm{V}}\right)}{\left(\mathrm{L}+\rho_{\mathrm{IV}}+\rho_{\mathrm{V}}\right)}$

onde piv e pv corresponde respectivamente as bandas do infravermelho próximo e do vermelho e L é constante, cujo valor mais 


\section{RBGF- Revista Brasileira de Geografia Física \\ Recife-PE Vol.1 n.02 Set/Dez 2008,30-49}

frequentemente usado é 0,5 (Accioly et al., 2002; Boegh et al., 2002; Silva et al., 2005).

\section{IAF}

O índice de área foliar é definido pela razão entre a área foliar de toda a vegetação por unidade de área utilizada por essa vegetação. Este índice é um indicador de biomassa de cada pixel da imagem sendo calculada pela equação empírica proposta por Allen et al. (2002) (Eq. 8).

$\mathrm{IAF}=-\frac{\ln \left(\frac{0,69-\mathrm{SAVI}}{0,59}\right)}{0,91}$

\section{Emissividades}

Para a obtenção da temperatura da superfície, é utilizada a equação de Planck invertida, válida para um corpo negro. Como cada pixel não emite radiação eletromagnética como um corpo negro, há a necessidade de introduzir a emissividade de cada pixel no domínio espectral da banda termal $\varepsilon_{\mathrm{NB}}$, qual seja: $10,4-12,5 \mu \mathrm{m}$. Por sua vez, quando do cômputo da radiação de onda longa emitida por cada pixel, há de ser considerada a emissividade no domínio da banda larga $\varepsilon_{0}(5-100 \mu \mathrm{m})$. Segundo Allen et al. (2002), as emissividades $\varepsilon_{\mathrm{NB}}$ (Eq. 9) e $\varepsilon_{0}$ (Eq. 10) podem ser obtidas, para NDVI > 0 e $\mathrm{IAF}<3$, segundo:

$\varepsilon_{\mathrm{NB}}=0,97+0,00331 \mathrm{IAF}$

Para pixels com $\quad \mathrm{IAF} \geq 3$, $\varepsilon_{\mathrm{NB}}=\varepsilon_{0}=0,98$. Para corpos de água (NDVI $<$ 0), no caso do lago de Sobradinho e do leite do Rio São Francisco, Silva \& Cândido (2004) utilizaram os valores de $\varepsilon_{\mathrm{NB}}=0,99$ e $\varepsilon_{0}=$ 0,985, conforme Allen e al. (2002).

\section{Temperatura da Superfície}

Para a obtenção da temperatura da superfície $\left(T_{s}\right)$ são utilizados a radiância espectral da banda termal $L_{\lambda, 6}$ e a emissividade $\varepsilon_{\mathrm{NB}}$ obtida na etapa anterior. Dessa forma, obtém-se a temperatura da superfície (K) (Eq. 11) pela seguinte expressão:

$\mathrm{T}_{\mathrm{s}}=\frac{\mathrm{K}_{2}}{\ln \left(\frac{\varepsilon_{\mathrm{NB}} \mathrm{K}_{1}}{\mathrm{~L}_{\lambda, 6}}+1\right)}$

onde $\quad \mathrm{K}_{1}=607,76 \mathrm{Wm}^{-2} \mathrm{sr}^{-1} \mu \mathrm{m}^{-1} \quad$ e $\quad \mathrm{K}_{2}$ $=1260,56 \mathrm{~K}$ são constantes de calibração da banda termal do Landsat 5-T (Allen et al., 2002; Silva et al., 2005).

\section{Radiação de Onda Longa Emitida}

A radiação de onda longa emitida pela superfície $\mathrm{R}_{\mathrm{L} \uparrow}\left(\mathrm{Wm}^{-2}\right)$ (Eq. 12) é obtida através da equação de Stefan-Boltzman:

$\mathrm{R}_{\mathrm{L} \uparrow}=\varepsilon_{0} \cdot \sigma \cdot \mathrm{T}_{\mathrm{s}}^{4}$

onde $\varepsilon_{0}$ é a emissividade de cada pixel, $\sigma$ é a constante de Stefan-Boltzman $\left(\sigma=5,67 \cdot 10^{-8} \mathrm{Wm}^{-2} \mathrm{~K}^{-4}\right)$ e $\mathrm{T}_{\mathrm{s}}$ é a temperatura da superfície $(\mathrm{K})$. 


\section{RBGF- Revista Brasileira de Geografia Física \\ Recife-PE Vol.1 n.02 Set/Dez 2008,30-49}

\section{Radiação de onda curta incidente}

A radiação de onda curta incidente $\mathrm{R}_{\mathrm{s} \downarrow}\left(\mathrm{Wm}^{-2}\right)($ Eq. 13) é o fluxo de radiação solar direta e difusa que atinge a superfície terrestre, que para condição de céu claro é dada pela seguinte expressão (Allen et al., 2002):

$\mathrm{R}_{\mathrm{s} \downarrow}=\mathrm{S} \cdot \cos Z \cdot \mathrm{d}_{\mathrm{r}} \cdot \tau_{\mathrm{sw}}$

onde $\mathrm{S}$ é a constante solar $\left(1367 \mathrm{Wm}^{-2}\right), \mathrm{Z}$ é ângulo zenital solar, $d_{r}$ é o inverso do quadrado da distância relativa Terra-Sol e $\tau_{\mathrm{sw}}$ é a transmissividade atmosférica. $R_{s \downarrow}$ pode ser considerado constante em toda a área de estudo, quando a mesma é de pequena dimensão.

\section{Radiação de onda longa incidente}

A radiação de onda longa incidente emitida pela atmosfera na direção da superfície $R_{L \downarrow}\left(\mathrm{Wm}^{-2}\right)($ Eq. 14), pode ser computada pela equação de StefanBoltzman:

$\mathrm{R}_{\mathrm{L} \downarrow}=\varepsilon_{\mathrm{a}} \cdot \sigma \cdot \mathrm{T}_{\mathrm{a}}^{4}$

onde $\varepsilon_{\mathrm{a}}$ é a emissividade atmosférica obtida por: $\quad \varepsilon_{\mathrm{a}}=0,85 \cdot\left(-\ln \tau_{\mathrm{sw}}\right)^{0,09} \quad($ Allen et al., 2002), o é a constante de Stefan-Boltzman e $\mathrm{T}_{\mathrm{a}}$ é a temperatura do ar (K).

\section{Saldo de radiação}

$\mathrm{O}$ saldo de radiação à superfície $\mathrm{Rn}$ $\left(\mathrm{Wm}^{-2}\right)($ Eq. 15)é computado utilizando-se a seguinte equação do balanço de radiação à superfície:

$R n=R_{s \downarrow}-\alpha R_{s \downarrow}+R_{L \downarrow}-R_{L \uparrow}-\left(1-\varepsilon_{o}\right) R_{L \downarrow}$

onde $R_{s \downarrow}$ é a radiação de ondas curtas incidente, $\alpha$ é o albedo corrigido de cada pixel, $R_{L \downarrow}$ é a radiação de onda longa emitida pela atmosfera na direção de cada pixel, $R_{L \uparrow}$ é a radiação de onda longa emitida por cada pixel e $\varepsilon_{o}$ é a emissividade de cada pixel.

\section{Fluxo de calor no solo}

O fluxo de calor no solo $\mathrm{G}\left(\mathrm{Wm}^{-2}\right)$

(Eq. 16) pode ser obtido segundo equação empírica desenvolvida por Bastiaanssen (2000), que representa os valores próximos ao meio-dia:

$\mathrm{G}=\left[\frac{\mathrm{T}_{\mathrm{s}}}{\alpha}\left(0,0038 \alpha+0.0074 \alpha^{2}\right)\left(1-0,98 \mathrm{NDVI}^{4}\right)\right] \mathrm{Rn}$

onde $\mathrm{T}_{\mathrm{s}}$ é a temperatura da superfície $\left({ }^{\circ} \mathrm{C}\right), \alpha$ é o albedo da superfície e NDVI é o índice de vegetação da diferença normalizada, todos computados pixel a pixel. Para efeito de correção dos valores do fluxo de calor no solo para corpos de água $(\mathrm{NDVI}<0)$, pode ser utilizada a seguinte expressão: $G=0,3 R n$, usada por Silva \& Cândido (2004) ou G = 0,5Rn, segundo Allen et al.(2002).

\section{Mapa de Uso e Cobertura do solo}

O mapa de Uso e Cobertura do solo da Bacia Hidrográfica do Rio Moxotó foi o elaborado pela Companhia de Pesquisa em 


\section{RBGF- Revista Brasileira de Geografia Física \\ Recife-PE Vol.1 n.02 Set/Dez 2008,30-49}

Recursos Minerais (CPRM, 2004). Vale salientar que este mapa contempla a geometria e a distribuição das unidades vegetais, não atendendo as características fitológicas das mesmas.

\section{RESULTADOS E DISCUSSÕES}

A Figura 2 apresenta o Albedo à superfície estimado na bacia hidrográfica do rio Moxotó - PE. Nota-se que os valores mais baixos de albedo são os que contêm corpos hídricos. No dia 27 de setembro de 1992 é possível observar que a barragem Poço da Cruz, ficou na classe que apresentava variação de albedo entre $10 \%$ e $20 \%$, porém no dia 12 de outubro de 2003 o mesmo foi classificado entre 0 e $10 \%$. Valores semelhantes foram encontrados e validados por Silva et al (2006) em reservatórios d'água e no leito do Rio São Francisco em pesquisa realizada em Petrolina PE.
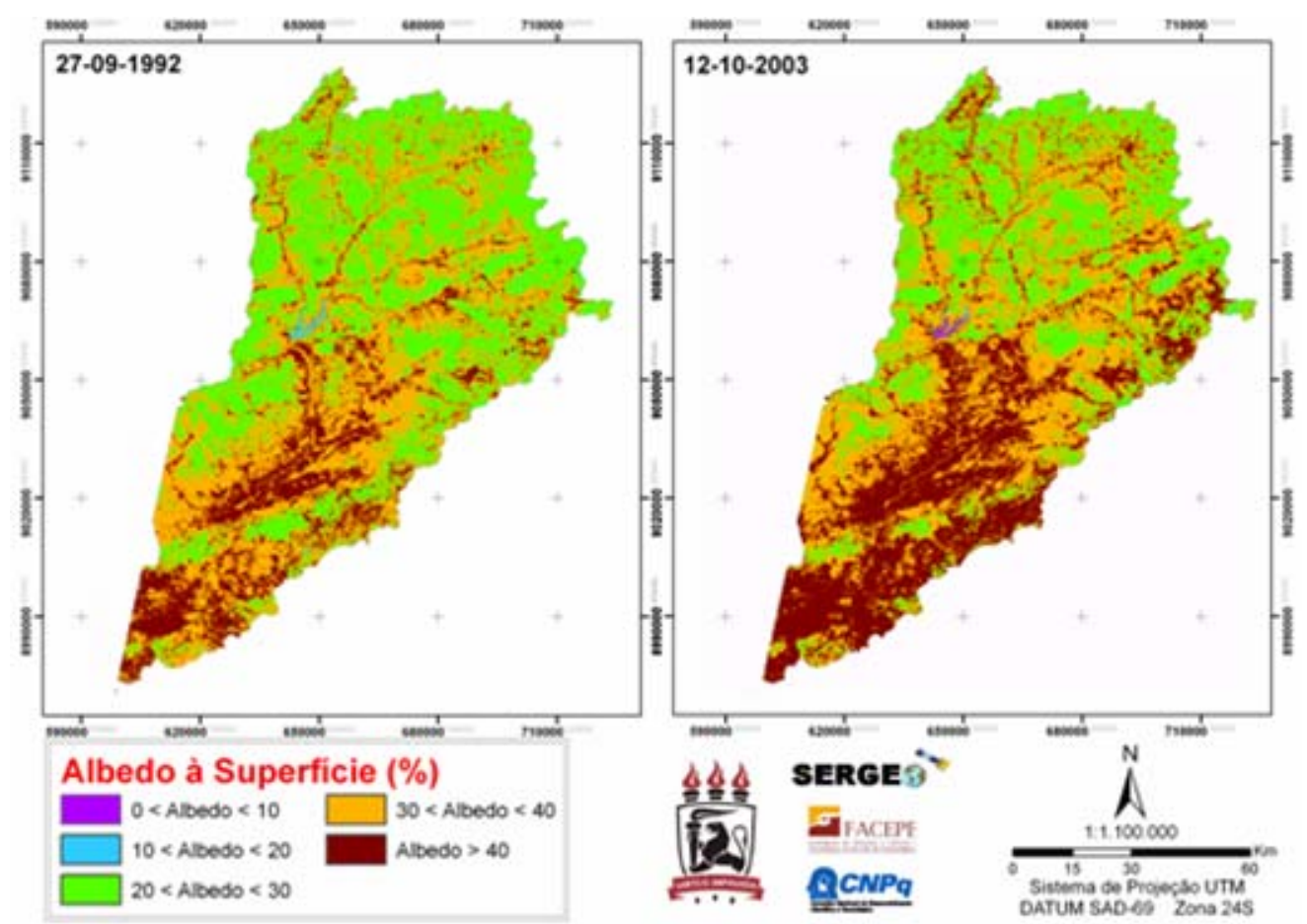

Figura 2. Albedo à superfície para os dias 27 de setembro de 1992 e 12 de outubro de 2003 em porcentagem

Na Tabela 2 é possível observar que todas as classes de Albedo, excetuando a classe de $\alpha>40$, ocorreram uma diminuição espacial na bacia hidrográfica do rio
Moxotó. Esta diminuição fica mais evidente na classe de albedo que varia entre 20 e 30 , que chegou a diminuir $12.29 \%$ entre as datas estudadas. Já na classe da $\alpha>40$ ocorreu um 


\section{RBGF- Revista Brasileira de Geografia Física \\ Recife-PE Vol.1 n.02 Set/Dez 2008,30-49}

aumento de $13.17 \%$ evidenciando um nativa e áreas de agricultura irrigada o albedo aumento espacial nesta classe de albedo na bacia hidrográfica do rio Moxotó, principalmente no médio e baixo Moxotó.

Tabela 2. Distribuição em porcentagem das classes de Albedo da Bacia Hidrográfica do Rio Moxotó

\section{Classe de}

$\begin{array}{lcc}\text { Albedo (\%) } & \text { 27/9/1992 } & \mathbf{1 2 / 1 0 / 2 0 0 3} \\ 0<\alpha<10 & - & 0.13 \\ 10<\alpha<20 & 0.51 & 0.31 \\ 20<\alpha<30 & 42.20 & 29.91 \\ 30<\alpha<40 & 40.76 & 39.95 \\ \alpha>40 & 16.50 & 29.67\end{array}$

Silva et al (2006), em estudo realizado no município de Petrolina, na região nordeste do Brasil, observou que áreas com presença de solo exposto e área urbana apresentaram valores de albedo superiores a 35\%. Já áreas com vegetação variou entre $10 \%$ e $25 \%$, o que também foi verificado em estudo realizado por Novas (2008), em área do estado de Alagoas e Bastiaanssen (2000) na bacia do Rio Gediz, na Turquia. As áreas que apresentaram $\alpha>40$ correspondem a áreas de solo exposto ou com desenvolvimento de atividades antrópicas, que pode ser observado através do mapa de uso e ocupação do solo da bacia hidrográfica do rio Moxotó-PE, Figura 3, elaborado pela CPRM (2004). Comparando a Figura 2 com a Figura 1 nota-se que nas áreas onde apresentam os valores de albedo superior a $40 \%$ são as áreas que apresentam algum tipo de atividade antrópica na bacia hidrográfica. Como mostrado na Figura 1 um aumento espacial do albedo acima de $40 \%$ pode indicar um aumento do uso antrópico na bacia em estudo.

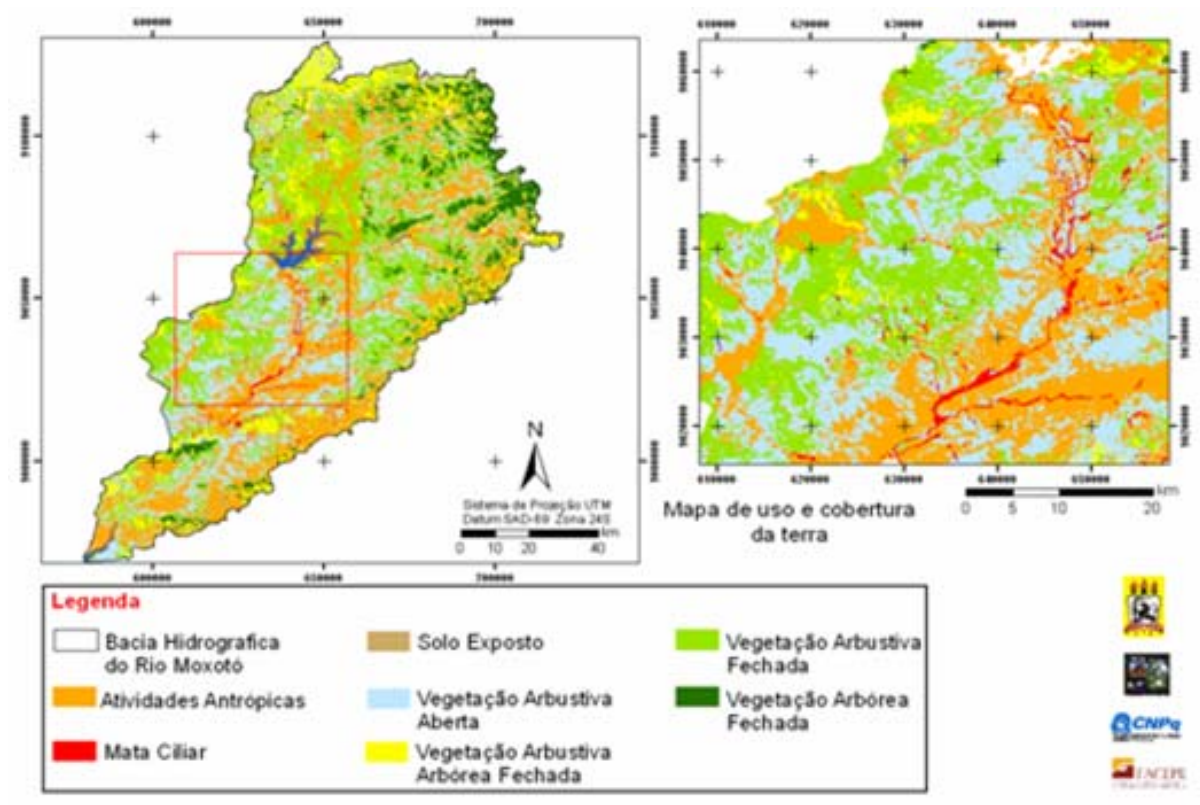

Figura 3 - Uso e cobertura do solo da Bacia Hidrográfica do Rio Moxotó. Adaptado de CPRM, 2004.

Oliveira, T. H. \& Galvíncio, J. D. 


\section{RBGF- Revista Brasileira de Geografia Física \\ Recife-PE Vol.1 n.02 Set/Dez 2008,30-49}

A Figura 4 apresenta o SAVI estimado para a bacia hidrográfica do rio Moxotó nas datas de 27 de setembro de 1992 e 12 de outubro de 2003. Nota-se que ocorreu uma perda de cobertura vegetal na margem leste e noroeste da bacia e que influenciou no aumento de albedo destas áreas. É necessário esclarecer que o aumento do albedo e a perda de cobertura vegetal também está atrelada as variações físicas naturais do bioma caatinga. Entre setembro e outubro na bacia em estudo é normal ocorrer perda de cobertura vegetal. Essa perda se dá devido à caatinga ser um bioma que sofre com estresse hídrico e perde suas folhas. Essa particularidade do bioma caatinga ocorre para que ela evite a perda de água através da evapotranspiração. Realizando a análise comparativa entre o mapa de SAVI, Figura 4, e o mapa de Elevação (m) e declividade $\left(^{\circ}\right)$, Figura 5, é possível visualizar que a altitude exerce influência na distribuição vegetal da bacia. As áreas com altitudes acima de 600m, áreas de cimeira, apresentaram índices de SAVI com valores superiores a 0.211. Já as áreas com vegetação de encosta apresentaram valores de SAVI que variaram entre $0.130 \mathrm{e}$ 0.210 .
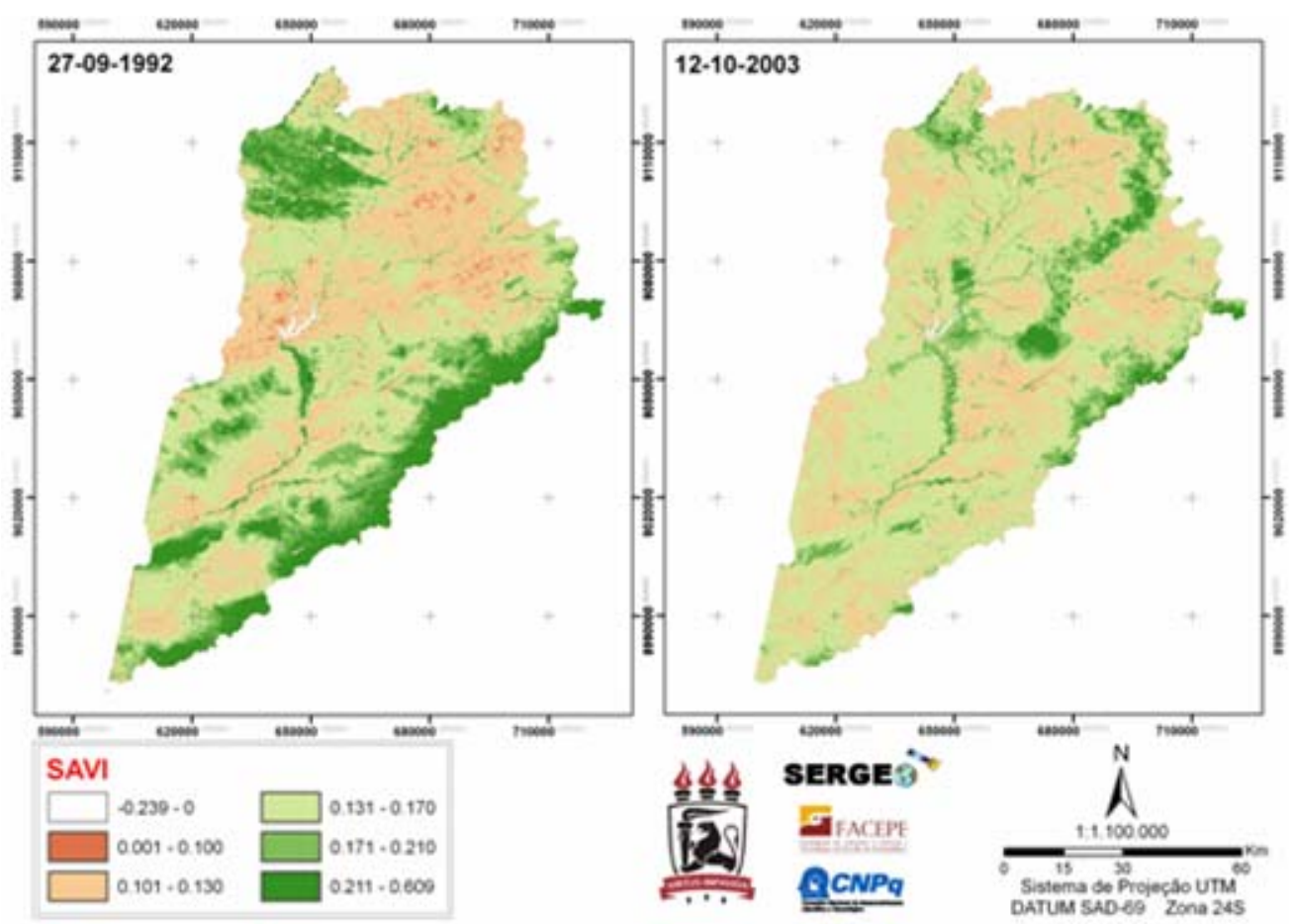

Figura 4. Índice de Vegetação ajustado ao efeito do solo (SAVI) dos dias de 27 de setembro de 1992 e 12 de outubro de 2003 para a bacia Hidrográfica do Rio Moxotó 


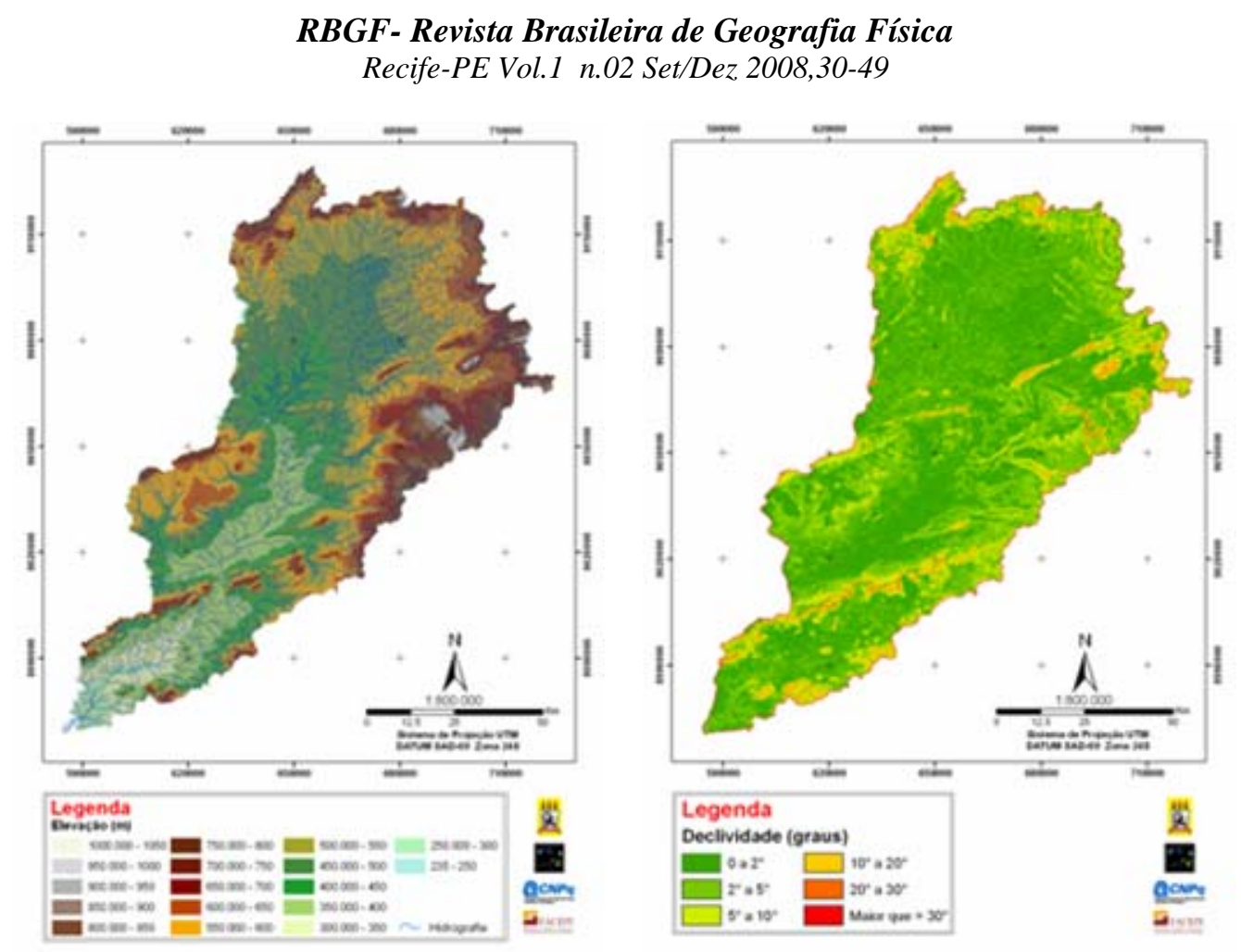

Figura 5. Elevação (m) e Declividade $\left(^{\circ}\right)$ para a Bacia Hidrográfica do rio Moxotó

Na Figura 6 é possível observar os histogramas de freqüência do SAVI para as datas de 27 de setembro de 1992 e 12 de outubro de 2003, respectivamente, com os seus valores médios representados pela linha vermelha. Nota-se que a maior freqüência do SAVI para a imagem de 1992 foi de 0,15 e para 2003 foi de 0,13. Essa diminuição nos valores mais freqüentes da cobertura vegetal pode estar relacionada às variações climáticas entre os meses e ano em estudo. Giongo et al (2007) obtiveram para o SAVI os valores de $-0.214,0.521$ e 0.121 para mínimo, máximo e médio respectivamente, refletindo uma menor densidade de cobertura vegetal para a área estudada.
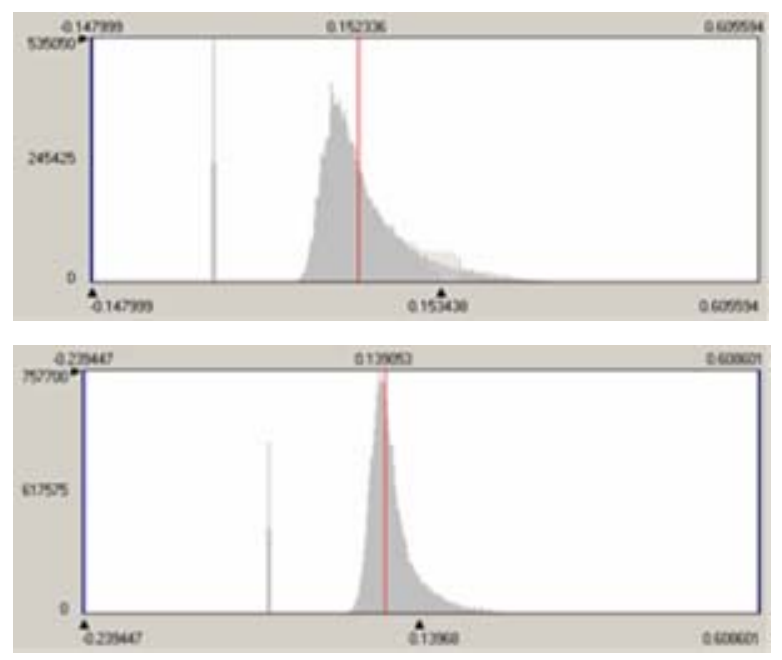

Figura 6. Histograma de freqüência de SAVI para os dias de 27 de setembro de 1992 e 12 de outubro de 2003 respectivamente.

As áreas com atividades antrópica apresentaram valores de SAVI que variaram entre 0.101 e 0.130 o que pode ser verificado através 


\section{RBGF- Revista Brasileira de Geografia Física \\ Recife-PE Vol.1 n.02 Set/Dez 2008,30-49}

do mapa de uso e ocupação do solo, Figura

3. Os baixos índices de vegetação encontrados são reflexos da época do ano em que as imagens utilizadas foram imageadas.

Através da confecção dos climogramas da média histórica de temperatura e precipitação dos municípios de Ibimirim-PE, Tacaratú-PE e Mata Grande-AL, elaborados através da utilização da média histórica obtidos no site do Departamento de Ciências Atmosféricas da UFCG, Figura 7, foi possível observar que os meses de setembro e outubro apresentam historicamente valores de precipitação muito baixo.

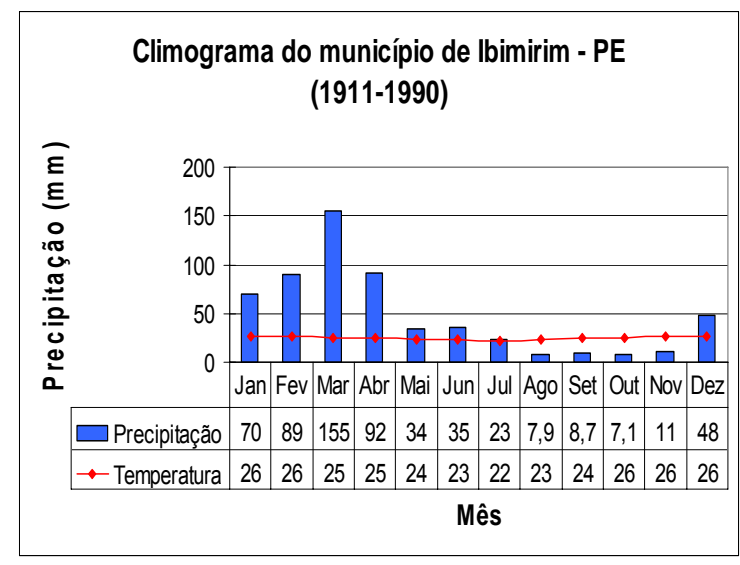

Climograma do município de Mata Grande - AL (1911-1990)

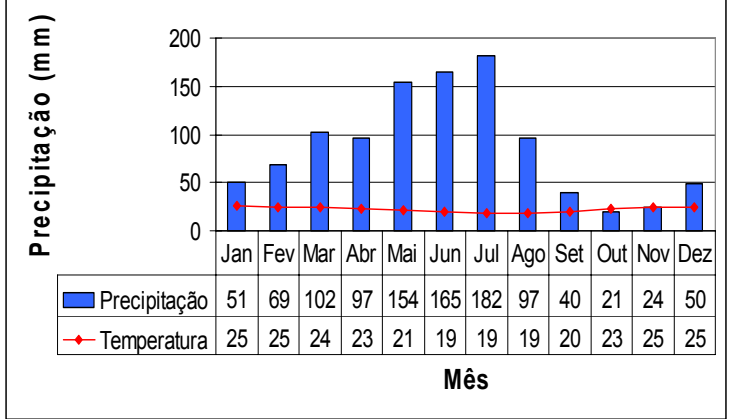

Climograma do município de Tacaratú - PE (1911-1990)

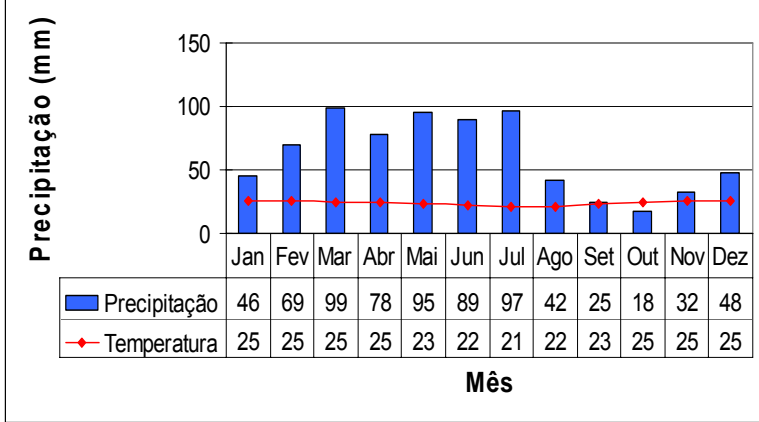

Figura 7. Climograma dos municípios de Ibimirim-PE, Tacaratú-PE Mata Grande-AL elaborados através da média histórica de precipitação e temperatura

A Figura 8 apresenta as variações de temperaturas à superfície no âmbito da bacia hidrográfica do rio Moxotó-PE para as datas de 27 de setembro de 1992 e 12 de outubro de 2003. Nota-se que as áreas onde ocorreu aumento nos valores do albedo e diminuição na cobertura vegetal apresentaram aumento na temperatura à superfície. Esse aumento espacial e temporal da temperatura é devido às mudanças naturais do clima adicionado às ações antrópicas. A diminuição da cobertura vegetal é evidente na análise temporal e espacial das duas datas analisadas, as áreas que apresentavam cobertura vegetal mais densa permaneceram com valores de temperatura variando entre $30^{\circ} \mathrm{C}$ e $35^{\circ} \mathrm{C}$, já as demais sofreram aumento de temperatura a superfície passando a apresentar valores variando entre $35^{\circ} \mathrm{C}$ e $38^{\circ} \mathrm{C}$ ou superiores a $38^{\circ}$. 


\section{RBGF- Revista Brasileira de Geografia Física}

Recife-PE Vol.1 n.02 Set/Dez 2008,30-49
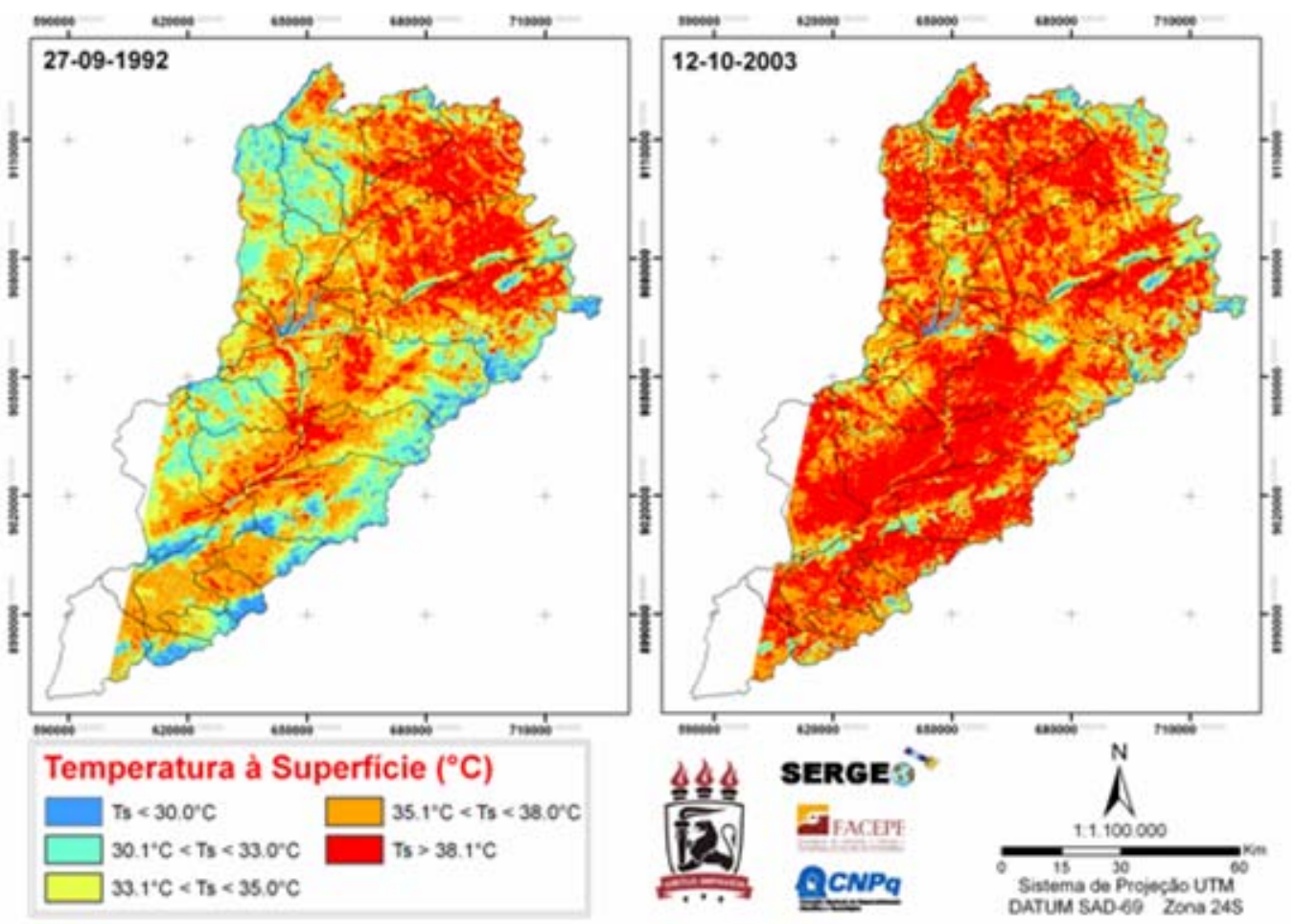

Figura 8. Temperatura à superfície dos meses de setembro de 1992 e outubro de 2003 para a bacia hidrográfica do Rio Moxotó

$\mathrm{Na}$ tentativa de se observar variações distribuídas sobre a bacia do Moxotó, se analisaram as variações de temperatura por microbacias hidrográficas de acordo com as apresentadas na Figura 9. Constata-se que as microbacias que sofreram diretamente com este aumento de temperatura foram as microbacias Riacho Caraibeiras, microbacia Riacho Pocinho, microbacia Riacho Dois Irmãos, microbacia Riacho do Socorro, microbacia Riacho Gravatá, microbacia Riacho Dois Riachos, microbacia Riacho Priapé, microbacia Riacho Coité, microbacia Rio Moxotó, microbacia Riacho do Copiti e

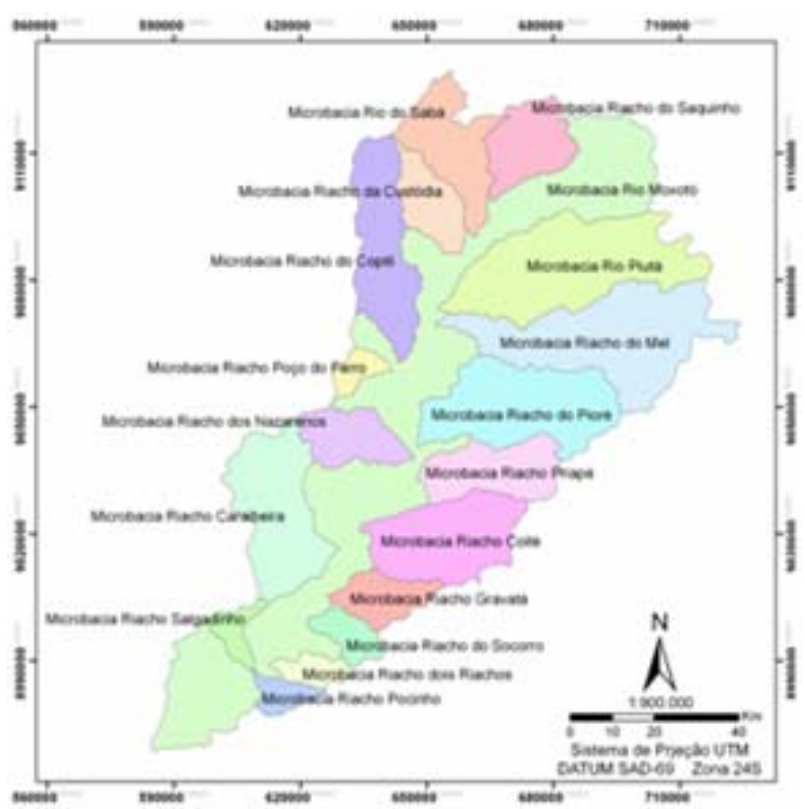

Figura 9. Microbacias hidrográficas da Bacia hidrográfica do rio Moxotó. Fonte CPRM (2004).

Riacho da Custódia. 


\section{RBGF- Revista Brasileira de Geografia Física}

Recife-PE Vol.1 n.02 Set/Dez 2008,30-49

O Saldo de Radiação (Rn) foi estimado para condições de céu claro, sem a presença de nebulosidade na área da bacia hidrográfica do Rio Moxotó para a passagem do satélite Landsat 5 nos dias 27 de setembro de 1992 e 12 de outubro de 2003. A Figura 10 apresenta os histogramas do saldo de radiação para as duas datas em estudo. Notase que ocorreu um aumento no saldo de radiação.

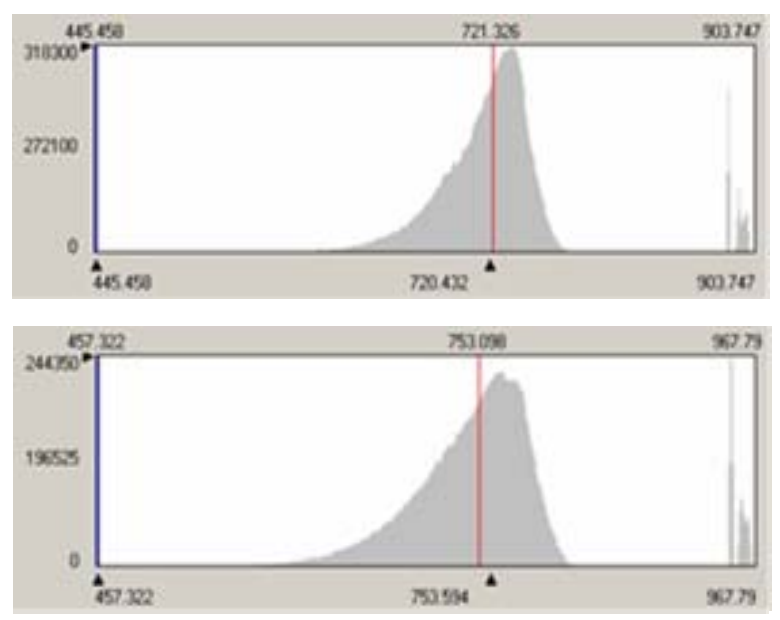

Figura 10. Histograma de freqüência do saldo de radiação para os dias de 27 de setembro de 1992 e 12 de outubro de 2003 respectivamente.

As áreas que apresentaram os menores valores do saldo de radiação, $\mathrm{Rn}<$ $400,00 \mathrm{~W} / \mathrm{m}^{2}$ (Figura 11), são as áreas que apresentaram as maiores temperaturas (Figura 8) e maiores valores de Albedo (Figura 2), com temperaturas superiores a $38^{\circ} \mathrm{C}$ e albedo $>40 \%$, respectivamente para a bacia hidrográfica e baixos valores de SAVI (Figura 4). Essas áreas são mapeadas pela CPRM (Figura 3) como áreas com atividades antrópicas. Já as áreas que mostraram os valores mais elevados para a bacia $(\mathrm{Rn}>$ $650.00 \mathrm{~W} / \mathrm{m}^{2}$ ) são os que apresentam corpos hídricos ou uma vegetação com maior densidade. Em geral, o saldo de radiação da bacia hidrográfica do rio Moxotó apresenta-se entre 400 e $500 \mathrm{~W} / \mathrm{m}^{2}$ para o ano de 1992 se intensificando mais ainda para o ano de 2003. Em estudo realizado na bacia do Rio Heihe na China, Bastiaanssen et al (1998b), encontrou valores em torno de $650 \mathrm{~W} / \mathrm{m}^{2}$ para áreas com oásis e $400 \mathrm{~W} / \mathrm{m}^{2}$ para regiões desérticas.

A Figura 12 apresenta o fluxo de calor no solo estimado para a bacia hidrográfica do rio Moxotó. Em geral, o fluxo de calor no solo esteve acima de $100 \mathrm{~W} / \mathrm{m}^{2}$ para o ano de 2003. Percebe-se um aumento acima de $20 \mathrm{~W} / \mathrm{m}^{2}$ no fluxo de calor no solo nas áreas que foram desmatadas.

Nessas áreas desmatadas, ocorreu um aumento de temperatura em torno de $5^{\circ} \mathrm{C}$. Nas áreas que não ocorreram alteração na cobertura vegetal o aumento no fluxo de calor no solo esteve em torno de $5 \mathrm{~W} / \mathrm{m}^{2}$. Isso mostra a interferência natural no fluxo de calor no solo adicionado as ações antrópicas na bacia hidrográfica do rio Moxotó-PE. 


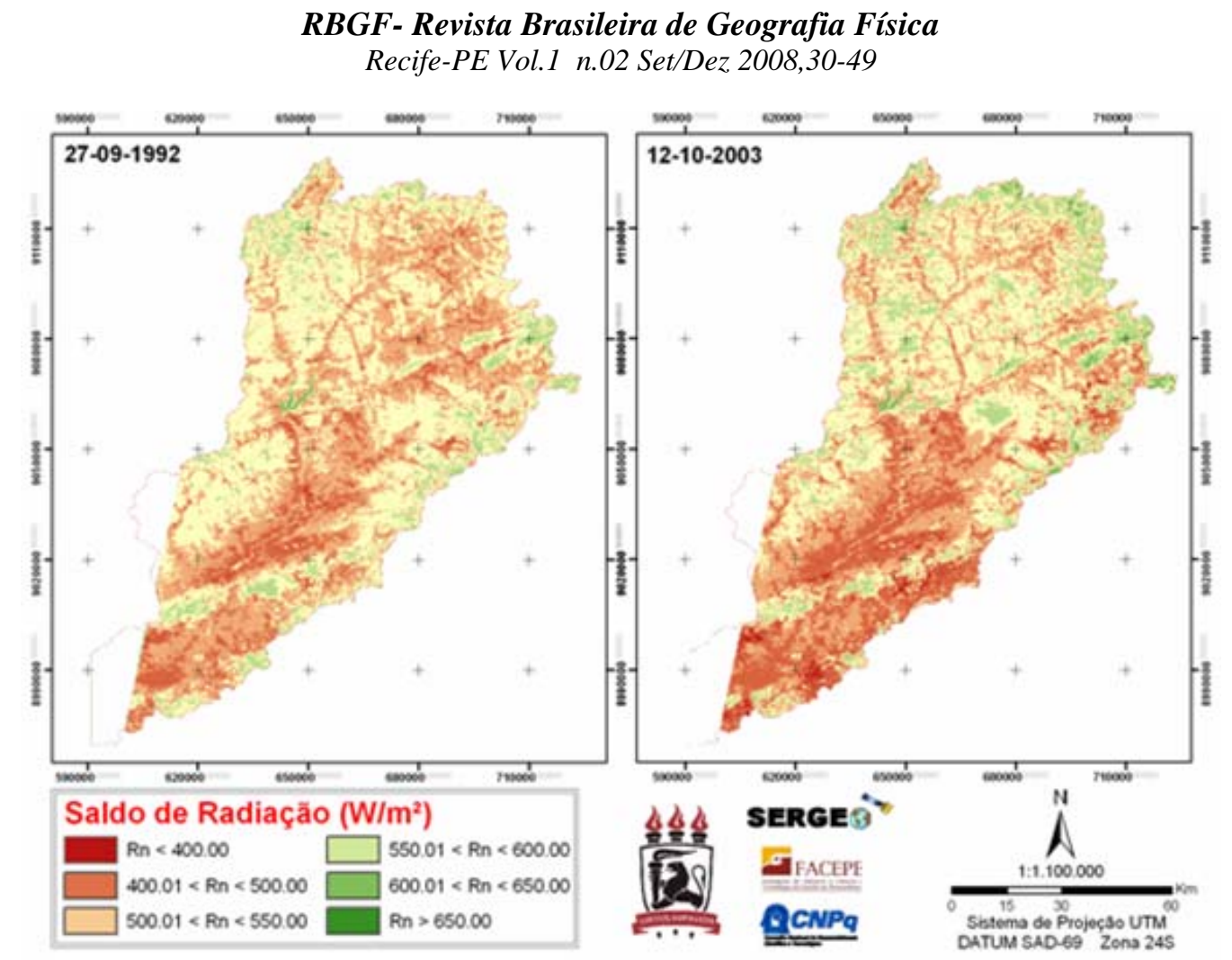

Figura 11. Saldo de Radiação para os dias de 27 de setembro de 1992 e 12 outubro de 2003 para a bacia Hidrográfica do Rio Moxotó.
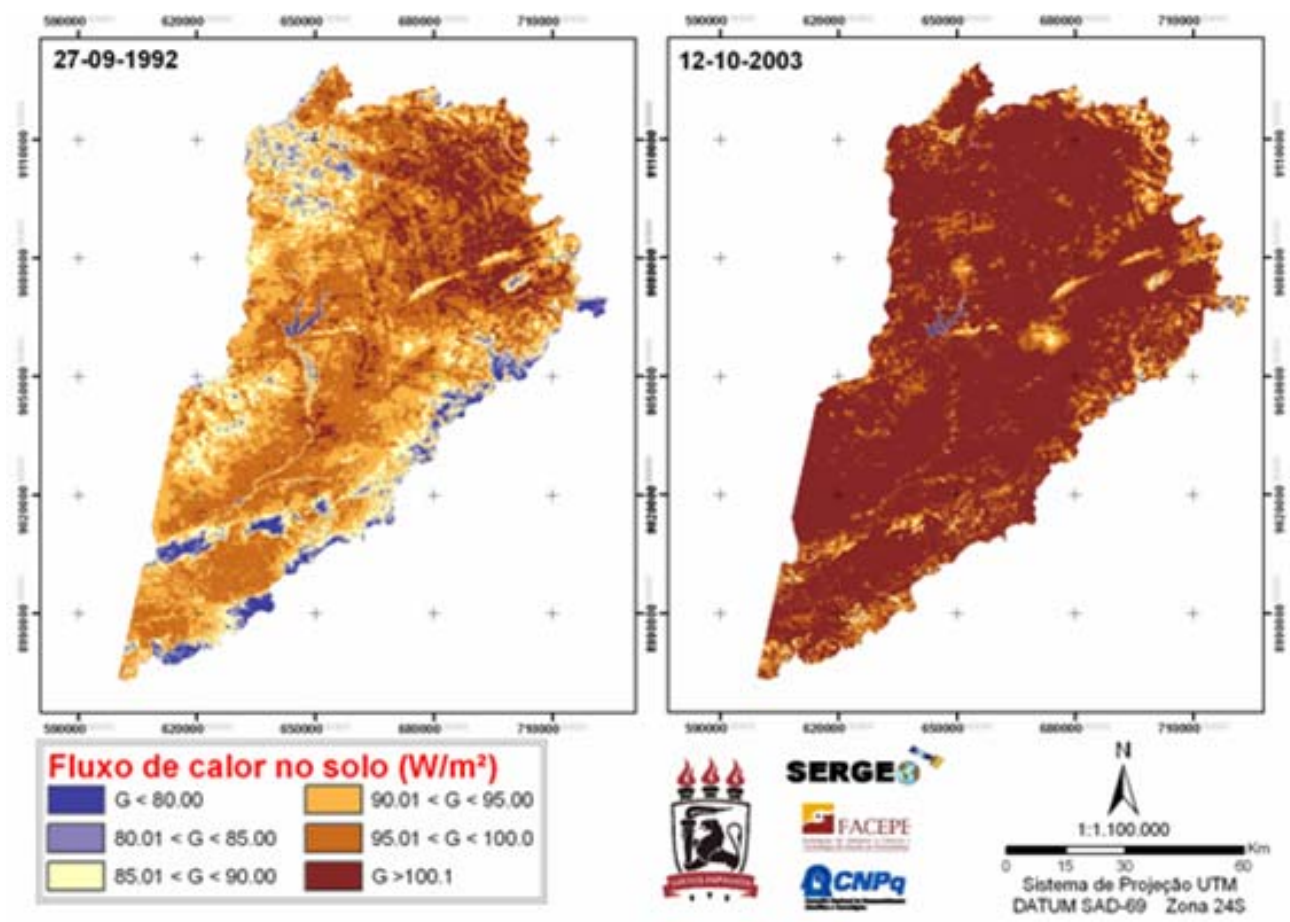

Figura 12. Fluxo de calor no solo para a bacia Hidrográfica do Rio Moxotó nos dias de 27 de setembro de 1992 e 12 outubro de 2003. 


\section{RBGF- Revista Brasileira de Geografia Física \\ Recife-PE Vol.1 n.02 Set/Dez 2008,30-49}

As áreas mais elevadas apresentaram os valores de fluxo de calor no solo mais baixos para a bacia. Porém entre as datas estudadas as áreas com altitudes superiores a $500 \mathrm{~m}$ sofreram um aumento de $10 \mathrm{~W} / \mathrm{m}^{2}$. Já a densidade de cobertura vegetal também demonstra ser um importante fator para a diminuição dos valores de fluxo de calor no solo.

\section{CONCLUSÃO}

Em geral, ocorreu um aumento do Albedo, entre 27 de agosto de 1992 e 12 de setembro de 2003 e na bacia hidrográfica do rio Moxotó.

As áreas de cimeira apresentaram índices de SAVI com valores superiores a 0.211. Já as áreas com vegetação de encosta apresentaram valores de SAVI que variaram entre 0.130 e 0.210 .

A diminuição da cobertura vegetal é evidente na análise temporal e espacial das duas datas analisadas, as áreas que apresentavam cobertura vegetal mais densa permaneceram com valores de temperatura variando entre $30^{\circ} \mathrm{C}$ e $35^{\circ} \mathrm{C}$, já as demais sofreram aumento de temperatura a superfície passando a apresentar temperaturas variando entre $35^{\circ} \mathrm{C}$ e $38^{\circ} \mathrm{C}$ e superiores a $38^{\circ} \mathrm{C}$.
Em geral, o fluxo de calor no solo esteve acima de $100 \mathrm{~W} / \mathrm{m}^{2}$ para o ano de 2003. Ocorreu um aumento acima de $20 \mathrm{~W} / \mathrm{m}^{2}$ no fluxo de calor no solo nas áreas que foram desmatadas. Nessas áreas desmatadas, ocorreu um aumento de temperatura em torno de $5^{\circ} \mathrm{C}$. Nas áreas que não ocorreram alteração na cobertura vegetal o aumento no fluxo de calor no solo esteve em torno de $5 \mathrm{~W} / \mathrm{m}^{2}$. Isso mostra a interferência natural no fluxo de calor no solo adicionado as ações antrópicas na bacia hidrográfica do rio Moxotó-PE.

\section{AGRADECIMENTOS}

Ao Conselho Nacional de Desenvolvimento Científico e Tecnológico (CNPQ) pela concessão de Bolsa de Iniciação Científica (PIBIC - UFPE), processo $n^{\circ}$ 121875/2008-3 e ao apoio financeiro através de Edital Universal processo ${ }^{\circ} 470746 / 2007-6$.

\section{REFERÊNCIAS}

ACCIOLY, L. J.; PACHECO, A.; COSTA, T. C. C.; LOPES, O. F.; OLIVEIRA, M. A. J. Relações empíricas entre a estrutura da vegetação e dados do sensor TM/Landsat. Revista Brasileira de Engenharia Agrícola e Ambiental, v.6, n.3, p.492-498, 2002.

ALLEN, R.G., TASUMI, M. and TREZZA, R. SEBAL (Surface Energy Balance Algorithms for Land). Advance Training and Users Manual - Idaho Implementation, version 1.0, 97p., 2002. 


\section{RBGF- Revista Brasileira de Geografia Física \\ Recife-PE Vol.1 n.02 Set/Dez 2008,30-49}

ALLEN, R. G., TREZZA, R. \& TASUMI M. Surface energy balance algorithms for land. Advance training and users manual, version 1.0, pp.98, 2002.

AZEVEDO, P.V.; LEITÃO, M.M.V.B.R.; SOUSA, I.F.; MACIEL, G.F. Balanço de radiação sobre culturas irrigadas no semiárido do Nordeste do Brasil. Revista Brasileira de Meteorologia, Rio de Janeiro, v.5, n.1, p.403-410, 1990.

BALDOCCHI, D. D.; MEYERS, T. P. On using ecophysiological, micrometeorological and biogeochemical theory to evaluate carbon dioxide, water vapor and trace gas fluxes over vegetation: a perspective. Agricultural and Forest Meteorology, v.90, n. 1, p. 1- 25, mar. 1998.

BASTIAANSSEN, W. G. M.; MENENTI, M.; FEDDES, R. A. \& HOLTSLAG, A. A. M. A. Remote Sensing Surface Energy Balance Algorithm for Land (SEBAL) 1. Formulation. Journal of Hydrology, v. 212213, p. 198-212, 1998 a.

BASTIAANSSEN, W. G. M., PELGRUM H., WANG, J. MORENO, Y. M.J., ROERINK, G. J. \& VAN DER WAL, T. The Surface Energy Balance Algorithm for Land (SEBAL) 2. Validation. Journal of Hydrology, 212-213: 213-229, 1998 b.

BASTIAANSSEN, W. G. M. SEBAL Based sensible and latent heat fluxes in the irrigated Gediz Basin, Turkey. Journal of Hydrology, v. 229, p. 87-100, 2000.

BLAD, L. B., BAKER, D. G. Reflected radiation from a soybean crop. Agronomy Journal, Madison, v.64, p. 277-281, 1972.

BOEGH, E., SOEGAARD, H. \& THOMSEN, A. Evaluating evapotranspiration rates and surface conditions using Landsat $\mathrm{TM}$ to estimate atmospheric resistance and surface resistance. Remote Sensing of Environment, 79:329-343, 2002.

CABRAL， O.M.R.; McWILLIAN， A.L.C.; ROBERTS, J.M. In-canopy microclimate of Amazonian forest and estimates of transpiration. In: Gash, J.H.C. et al. Amazonian deforestation and climate. New York: John Wiley \& Sons, 1996. p. 207-220.

CPRM. Base de Dados Geoambientais da Bacia Hidrográfica do Rio Moxotó - PE. Programa Hidrogeologia do Brasil, v. 1.1, 2004.

CRITCHFIELD, H.J. General Climatology. Englewood Cliffs: Prentice-Hall, 1974. 447p.

DUBAYAH, R. Estimating Net Solar Radiation using Landsat TM and Digital Elevation data Water Resources Research, 28 (a): 2469-2484, 1992.

GATES, D. M. (1965). Radiant energy, its receipt and disposal. Agricultural Meteorology , Meteorology Monograph. v.6, p.1-26. Boston: American Meteorological Society.

GIONGO, P. R.; MOURA, G. B. A.; RÊGO, P. L.; MEDEIROS, S. R. R. Índices de vegetação NDVI, SAVI e IAF estimados com imagens Landsat 5 - TM. VII Jornada de Ensino, Pesquisa e Extensão. Recife - PE. Imprensa Universitária, UFRPE, 2007.

GIAMBELLUCA, T.W. et al. Observations of albedo and radiation balance over postforest surfaces in the Eastern Amazon basin. Journal of Climate, Boston, v. 10, p. 919-928, 1997.

HOLL, K.D. Factors limiting tropical rain forest regeneration in abandoned pasture: seed rain, seed germination, microclimate, and soil. Biotropica, St. Louis, v. 31, n. 2, p. 229-242, 1999. 


\section{RBGF- Revista Brasileira de Geografia Física \\ Recife-PE Vol.1 n.02 Set/Dez 2008,30-49}

GRANGER, R.J. Satellite-derived estimates of evapotranspiration in the Gediz basin. Journal of Hydrology, v. 229, p. 70-76, 2000 .

HUETE, A. R. Adjusting vegetation indices for soil influences. International Agrophysics, v.4, n.4, p.367-376, 1988.

JARVIS, P. G.; MASSHERDER, J. M.; HALE, S. E.; MONCRIEFF, J. B.; RAYMENT, M.; SCOTT, S. L. Seasonal variation of carbon dioxide, water vapor, and energy exchanges of a boreal black spruce forest. Journal of Geophysical Research, v.102, n. D24, p. 28953-28966, 1997.

LEITÃO, M.M.V.B.R. Balanço de radiação e energia numa cultura de soja irrigada. Campina Grande, PB: UFPB, 1989. 110p. Dissertação Mestrado. DCA/CMM - TD N ${ }^{\circ}$ 03.

LEITÃO, M. DE M. V. B. R. Balanço de Radiação em três Ecossistemas da Floresta Amazônica: Campina, Campinarana e Mata Densa. Tese de Doutorado em Meterologia, aprovada em 07 de outubro de 1994 (INPE/MCT).

LIU, W. T. H.; KANAZAWA, P. S. (2003). Variabilidade climática e previsões: aplicabilidade dos satélites de observações ambientais como instrumento de planejamento do desenvolvimento local. Revista Internacional de Desenvolvimento Local.

MARKHAM, B. L.; BARKER, L. L. Thematic mapper bandpass solar exoatmospherical irradiances. International Journal of Remote Sensing, v.8, n.3, p.517523, 1987.

MORSE, A.; ALLEN, R. G., TASUMI, M., KRAMBER, W. J., TREZZA, R. \& WRIGHT, J. Application of the SEBAL Methodology for Estimating
Evapotranspiration and Consumptive Use of Water Through Remote Sensing. Final Report, 220 p, 2001.

NOVAS, M. F. B. Mapeamento das estimativas de saldo de radiação e índices de vegetação em área do estado de Alagoas com base em sensores remotos. Dissertação de Mestrado em Meteorologia. UFAL - Instituto de Ciências Atmosféricas, Maceió, 2008.

OLIVEIRA, G. M. de.; LEITÃO, M. de. M. v. b. r. 1. Estimativas de Evapotranspiração e as Conseqüências Devido aos Erros na Determinação de Saldo De Radiação e Efeitos Advectivos. Revista Brasileira de Engenharia Agrícola e Ambiental, v.4, n.3, p.343-347, 2000, Campina Grande, PB, DEAg/UFPB

OMETTO, J. C. Balanco de Radiacao Diaria e Razao de Insolacao. In: II SIMPOSIO BRASILEIRO DE ENERGIA SOLAR, 1973. JOAO PESSOA/PA. p. 0-0.

PERREIRA, L. de C. Caracterização do Balanço de Energia no Vale do Curaçá Bahia. Dissertação de mestrado do curso de Pós-graduação em Geofísica da Universidade Federal da Bahia, pp.81, 2006.

PITOMBO, L. R. M.; LISBOA, J. C. F. (2001). Matérias e substâncias. São Paulo: Ed. Pueri Domus, Escolas Associadas.

SILVA, B. B. da, LOPES, G. M. \& AZEVEDO, P. V. Determinação do albedo de áreas irrigadas com base em imagens Landsat 5 - TM. Revista Brasileira de Agrometeorologia. Aceito para publicação, 2004.

SILVA, B. B. da.; LOPES, G. M.; AZEVEDO, P. V. de. Balanço de radiação em áreas irrigadas utilizando imagens Landsat 5 - TM. Revista Brasileira de Meteorologia, v. 20, $\mathrm{n}$. 2, p. 243-252, 2005. 
SILVA, B. B. da; BEZERRA, M. V. C.;

BRAGA, A. C.; SILVA, S. T. A. da.

Obtenção de albedo de áreas irrigadas e de vegetação nativa em Petrolina e vizinhanças com imagens Landsat 7 - ETM+. Anais... III Simpósio Regional de Geoprocessamento e Sensoriamento Remoto, Aracaju/SE, 25 a 27 de outubro de 2006. 